\title{
Screening glioma stem cells in U251 cells based on the P1 promoter of the CD133 gene
}

\author{
XIAOFENG WANG $^{1}$, LU CHEN $^{2}$, ZHONGDI XIAO $^{3}$, YALI WANG $^{4 *}$, \\ TIEMEI LIU ${ }^{4 *}$, TIANFU ZHANG ${ }^{1 *}$ and YUCHENG ZHANG ${ }^{5 *}$
}

\author{
${ }^{1}$ Department of Stomatology, China-Japan Union Hospital, Jilin University, Changchun, Jilin 130033; \\ ${ }^{2}$ Department of Tumor and Blood Disease, The Affiliated Hospital to Changchun University of Chinese Medicine, \\ Changchun, Jilin 130021; ${ }^{3}$ Department of General Surgery, General Hospital of Daqing Oil Field, \\ Daqing, Heilongjiang 163001; ${ }^{4}$ Department of Blood Transfusion; ${ }^{5}$ Scientific Research Center, \\ China-Japan Union Hospital, Jilin University, Changchun, Jilin 130033, P.R. China
}

Received April 17, 2016; Accepted July 12, 2016

DOI: $10.3892 / 01.2016 .4966$

\begin{abstract}
Cluster of differentiation (CD)133 is an important cell surface marker of glioma stem cells (GSCs). The transcription of the CD133 gene is controlled by five alternative promoters (P1, P2, P3, P4 and P5), which are expressed in a tissue-specific manner. In the present study, gene recombination technology was used to construct two types of gene expression vectors that contained the $\mathrm{P} 1$ promoter of the CD133 gene, which regulated either the neomycin-resistance gene or the herpes simplex virus thymidine kinase (HSV-TK) gene. Following the stable transfection of U251 glioblastoma cells with these two gene vectors, the cells expressing the P1 promoter that regulated the neomycin-resistance gene were named CD133 (+) cells, while the cells expressing the P1 promoter regulating the HSV-TK gene were called CD133 (-) cells. The expression of CD133 was detected by flow cytometry and reverse transcription-quantitative polymerase chain reaction. The 3-(4,5-dimethylthiazol-2-yl)-2,5-diphenyltetrazolium bromide assay was used to assess cell proliferation ability, while the cell cycle was analyzed by flow cytometry, and a clone formation test was performed to evaluate the invasive capability of the cells. The results demonstrated that, due to CD133 expression, the cell proliferation ability and the invasive capability of CD133 (+) cells were significantly higher than those of CD133 (-) cells. In conclusion, the present study successfully established a novel method of screening GSCs in U251 cells based on the P1 promoter of the CD133 gene.
\end{abstract}

Correspondence to: Dr Yucheng Zhang, Scientific Research Center, China-Japan Union Hospital, Jilin University, 126 Xiantai Street, Changchun, Jilin 130033, P.R. China

E-mail: zhang4083@163.com

*Contributed equally

Key words: glioma stem cells, CD133, U251 cells, P1 promoter, screening

\section{Introduction}

Gliomas are the most common form of malignant primary brain tumor and one of the most lethal solid tumors, exhibiting a high rate of recurrence, poor survival rate and poor prognosis (1). An increasing number of reports in the literature have demonstrated that gliomas develop from multipotent cancer stem cells (CSCs), which are a group of cells with eternal life or infinite self-renewal ability that display high migrating, infiltrative and metastatic abilities (2). Although glioma stem cells (GSCs) only account for a small proportion $(1 \sim 10 \%)$ of the cells present in gliomas (3), they are considered to be responsible for the resistance of gliomas to traditional therapy, tumor recurrence and invasiveness (4). Therefore, effective sorting GSCs and elucidating the biological characteristics of GSCs are of great importance, and may be exploited in the development of novel therapeutic drugs for this deadly disease (5).

The first description of cluster of differentiation (CD)133 as a characteristic cell surface marker of GSCs was reported by Singh et al in 2004 (6). That study highlighted that only CD133-positive cells, which were sorted from human glioma samples, were capable of tumor initiation in vivo. Subsequently, increasing evidence has reported that $\mathrm{CD} 133$ has been widely used as a marker to characterize the CSC population in gliomas (7). CD133, also known as prominin-1, is a pentaspan transmembrane cell surface protein that is primarily localized to the plasma membrane (8). The transcription of the CD133 gene is controlled by five alternative promoters (P1, P2, P3, P4 and P5), with P1 exhibiting the highest activity in gliomas (9). The high expression of CD133 has been used to identify and isolate CSCs (10). There are two main methods for isolating CSCs from non-CSCs: Fluorescence-activated cell sorting (FACS) and magnetic-activated cell sorting (MACS) (11). However, these two sorting approaches present certain disadvantages, such as a low yield in the number of viable cells sorted (12).

In the present study, gene recombination technology was utilized to construct two types of gene expression vectors, and CD133 (+) U251 cells as well as CD133 (-) U251 cells 
were obtained. In addition, the present results illustrated that CD133 (+) cells had significantly higher CD133 expression, cell proliferation and cell invasive abilities than CD133 (-) cells.

\section{Materials and methods}

Cell line and cell culture. The U251 cell line was provided by the Department of Central Laboratory of the China-Japan Union Hospital of Jilin University (Changchun, China). The cells were cultured in Dulbecco's modified Eagle's medium (Gibco; Thermo Fisher Scientific, Inc., Waltham, MA, USA) supplemented with $10 \%$ fetal bovine serum (FBS) (Gibco; Thermo Fisher Scientific, Inc.), $100 \mathrm{U} / \mathrm{ml}$ penicillin $\mathrm{G}$ and $100 \mu \mathrm{g} / \mathrm{ml}$ streptomycin, and incubated in a humidified incubator at $37^{\circ} \mathrm{C}$ containing $5 \% \mathrm{CO}_{2}$.

Gene cloning and construction of gene vectors. The vectors pcDNA3.1, pMD18-T, pMD18-HSV-TK and pWPXLd were kindly provided by Dr Du Zhen-Wu (Jilin University, Changchun, China). The P1 promoter of the CD133 (1,810 bp), neomycin-resistance (795 bp) and herpes simplex virus thymidine kinase (HSV-TK) $(1,210 \mathrm{bp})$ genes were amplified by polymerase chain reaction (PCR) using specifically designed primer pairs. The sequences of the primer pairs were as follows: P1 promoter of the CD133 gene, forward 5'-GTAGTC GACCTTCAGTGCCTCTTTCAGT-3' and reverse 5'-GCC TTAATTAAGTGGGGATCTGCCTCAGTC-3'; P1 promoter of the neomycin-resistance gene, forward 5'-ACGCGTCGC ATGATTGAACAAGAT-3' and reverse 5'-ACTAGTCTC AGAAGAACTCGTCGTCAAG-3'; and P1 promoter of the HSV-TK gene, forward 5'-AAGGGATCCGCCATCATGGCC TCGTAC-3' and reverse 5'-TTCACTAGTCTCAGTTAGCCT CCCCCATC-3'. The PCR conditions used were as follows: $94^{\circ} \mathrm{C}$ for $5 \mathrm{~min}$, followed by $94^{\circ} \mathrm{C}$ for $45 \mathrm{sec}, 58^{\circ} \mathrm{C}$ for $45 \mathrm{sec}$ and $72^{\circ} \mathrm{C}$ for $45 \mathrm{sec}$ for 35 cycles, and a final extension of $72^{\circ} \mathrm{C}$ for $10 \mathrm{~min}$. The PCR products were analyzed by electrophoresis on a $1 \%$ agarose gel, and visualized with ethidium bromide. Upon cloning these PCR products into the pMD18-T vector, the vectors were identified by digestion with different restriction enzymes and sequencing. Finally, two types of lentiviral vectors with the $\mathrm{P} 1$ promoter of the $\mathrm{CD} 133$ gene regulating the neomycin-resistance gene (named pWPXLd-pCD133-Neo) and the HSV-TK gene (named pWPXLd-pCD133-HSV-TK) were constructed by gene recombination technology.

Packaging and titration of the lentiviral vectors. The lentiviral vectors and packaging components (psPAX2 and pMD2.G; Invitrogen; Thermo Fisher Scientific, Inc.) were transfected into 293 T cells with Lipofectamine 2000 (Invitrogen; Thermo Fisher Scientific, Inc). At $48 \mathrm{~h}$ post-transfection, the culture media containing the lentiviruses were harvested and filtered through a $0.45-\mathrm{mm}$ filter. Virus aliquots were suspended in medium without FBS, and stored at $-80^{\circ} \mathrm{C}$ until used.

CD133 (+) and CD133 (-) cells selection. When the U251 cells were $>90 \%$ confluent, different lentiviral vector particles were added into the cell culture medium. Selection of CD133 (+) cells containing the pWPXLd-pCD133-Neo vector was conducted by adding G418 (Gibco; Thermo Fisher Scientific, Inc.), while selection of CD133 (-) cells containing the
pWPXLd-pCD133-HSV-TK vector was performed by adding hygromycin B (Roche Applied Science, Pleasanton, CA, USA). Colonies were detected after 14 days in the selective medium, and independent colonies were trypsinized and transferred to 96-well plates. Finally, the cells were cultured routinely with G418 $(300 \mu \mathrm{g} / \mathrm{ml})$ or hygromycin B $(50 \mu \mathrm{g} / \mathrm{ml})$.

CD133 messenger (m)RNA expression by reverse transcriptionquantitative (RT-q)PCR. RT-qPCR was used to detect CD133 mRNA expression. Briefly, total RNA was extracted according to the manufacturer's protocol of the RNA extraction kit (Tiangen Biotech Co., Ltd., Beijing, China). First-strand complementary (c)DNA was synthesized using FastLane Cell cDNA kit (Tiangen Biotech Co., Ltd.), according to the manufacturer's protocol. The sequences of the primers used for RT-qPCR were as follows: CD133, forward 5'-TGGATG CAGAACTTGACAACGT-3' and reverse 5'-AGGCCACCC AGCCACCAGTA-3'; and glyceraldehyde 3-phosphate dehydrogenase, forward 5'-TGCACCACCAACTGCTTAGC-3' and reverse 5'-GGCATGGACTGTGGTCATGAG-3'. PCR was initiated with a denaturation of $5 \mathrm{~min}$ at $95^{\circ} \mathrm{C}$, followed by 35 cycles of $95^{\circ} \mathrm{C}$ for $30 \mathrm{sec}$ and $58^{\circ} \mathrm{C}$ for $30 \mathrm{sec}$, and a final elongation of $72^{\circ} \mathrm{C}$ for $10 \mathrm{~min}$, using GeneAmp ${ }^{\circledR} \mathrm{PCR}$ System 9700 (Applied Biosystems; Thermo Fisher Scientific, Inc.). The mRNA expression of CD133 was determined from each group of U251 cells, and the experiments were performed in triplicate. Relative quantification using the comparative $\mathrm{Cq}$ method was conducted for each group (13).

CD133 protein expression analysis by flow cytometry. U251 cells from each group were seeded in 6-well plates at a density of $5 \times 10^{4}$ cells/well. After the cells were cultured for $72 \mathrm{~h}$, different groups of cells were trypsinized to prepare a single cell suspension. Flow cytometry analysis was performed as described elsewhere (14). Briefly, cells were washed with chilled phosphate-buffered saline (PBS) and resuspended with mouse anti-CD133-phycoerythrin antibody (cat. no. 130-098826; 1:1,000; Miltenyi Biotec GmbH, Bergisch Gladbach, Germany) or with fluorophore-tagged isotype controls (cat. no. 130-098-845; 1:1,000; Miltenyi Biotec $\mathrm{GmbH}$ ) for $30 \mathrm{~min}$ at $4^{\circ} \mathrm{C}$. Cells were then washed twice with PBS and resuspended in PBS for analysis. Flow cytometry analysis was conducted with a flow cytometer (FC500; Beckman Coulter, Inc., Brea, CA, USA). Cell debris and aggregates were excluded based on scatter signals, and 10,000 events/sample were captured. Data were analyzed using CXP software (Beckman Coulter, Inc.).

Cell cycle analysis by flow cytometry. Cell cycle analysis was performed as previously described (15). Briefly, different groups of cells were harvested as single cell suspensions and fixed with $70 \%$ ice-cold ethanol at $-20^{\circ} \mathrm{C}$ overnight. Then, the cells were washed and resuspended in PBS, followed by incubation with propidium iodide $(10 \mathrm{mg} / \mathrm{ml}$; Sigma-Aldrich, St. Louis, MO, USA) and RNase A (Sigma-Aldrich) for $30 \mathrm{~min}$ at $4^{\circ} \mathrm{C}$. Finally, the cell cycle distribution was measured by flow cytometry (FC500; Beckman Coulter, Inc.), and the results were analyzed by MultiCycle software (Beckman Coulter, Inc.). The proliferative index was defined as the percentage of cells in the $\mathrm{S}+\mathrm{G} 2 / \mathrm{M}$ phases divided by the total number of cells in the $(\mathrm{G} 0 / \mathrm{G} 1+\mathrm{S}+\mathrm{G} 2 / \mathrm{M})$ phases and multiplied by $100(16)$. 


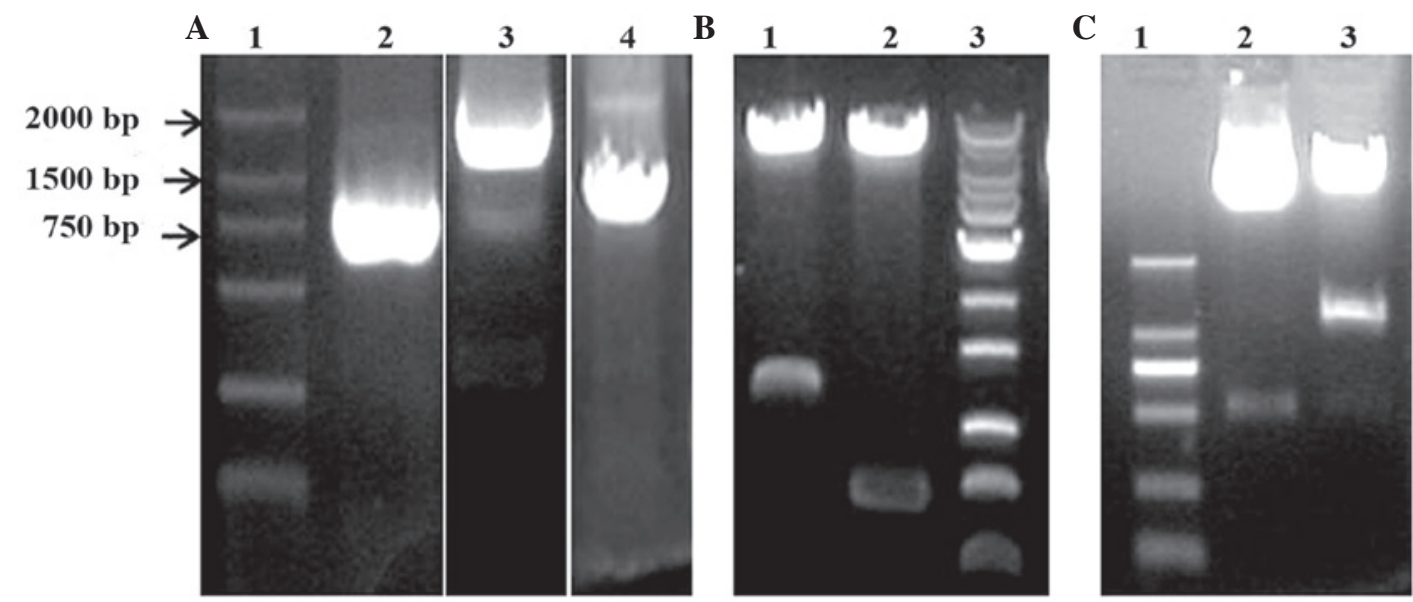

Figure 1. Gene cloning and identification of pWPXLd-pCD133-Neo and pWPXLd-pCD133-HSV-TK. (A) Agarose gel electrophoresis of polymerase chain reaction products. Lanes 1, 2, 3 and 4 represent DNA marker DL2000, and the P1 promoter of the neomycin-resistance, CD133 and HSV-TK genes, respectively. (B) Identification of pWPXLd-pCD133-Neo by gel electrophoresis upon digestion with different pairs of restriction enzymes. Lane 1 represents the result of digestion with $\underline{P a c} \mathrm{I}$ and $\underline{S a l I}-\mathrm{HF}$ enzymes; lane 2 represents the result of digestion with $\underline{S p e I}$ and $M l u I$ enzymes; and lane 3 represents 1 kb Plus DNA Ladder. (C) Identification of pWPXLd-pCD133-HSV-TK by gel electrophoresis upon double digestion with restriction enzymes. Lanes 1,2 and 3 correspond to the DL2000 DNA Marker, and the results of digestion with PacI and SalI restriction enzymes, respectively. HSV-TK, herpes simplex virus thymidine kinase; $\mathrm{CD}$, cluster of differentiation.

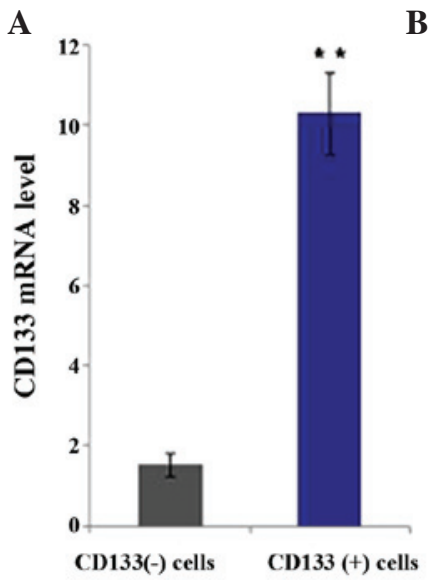

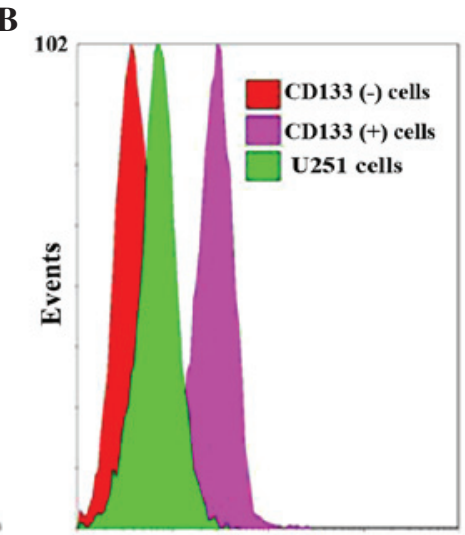

CD133 protein expression
C

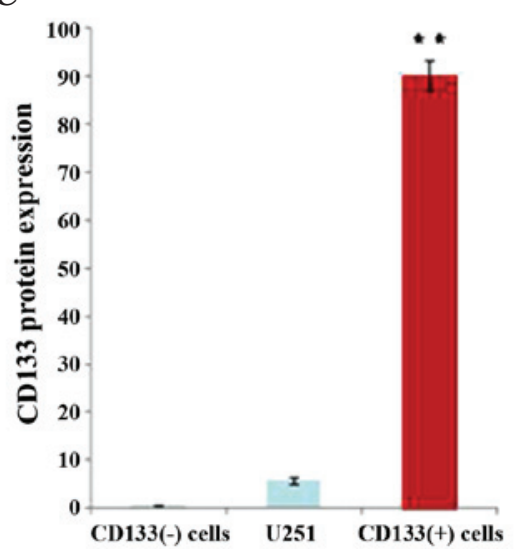

Figure 2. The mRNA and protein expression levels of CD133 were determined by qPCR and flow cytometry in different cell groups. RNA from each group of cells was extracted, transcribed and evaluated via qPCR. Glyceraldehyde 3-phosphate dehydrogenase was used as an endogenous reference for normalization. The three groups of cells (CD133-positive, CD133-negative and control) were stained with an anti-CD133-phycoerythrin antibody, and CD133 protein expression was analyzed by flow cytometry. (A) CD133 mRNA expression was quantified based on the results from three experiments. (B) The overlay plot of flow cytometry was representative of three repeated experiments. (C) The CD133 protein expression results were quantified based on the findings from three experiments, and were represented as the mean \pm standard deviation. ${ }^{* *} \mathrm{P}<0.05$ vs. control. qPCR, quantitative polymerase chain reaction; $\mathrm{CD}$, cluster of differentiation; mRNA, messenger RNA.

Values were represented as the mean \pm standard error of the mean (SEM) of three independent experiments performed in triplicate.

Cell proliferation analysis by 3-(4,5-dimethylthiazol-2-yl)2,5-diphenyltetrazolium bromide (MTT) assay. The cell proliferation assay was performed in all cell groups as previously described (17). Briefly, $20 \mu$ l MTT $(5 \mathrm{mg} / \mathrm{ml}$; Sigma-Aldrich) was added into each well daily from days 1 to 7 , and plates were incubated for $4 \mathrm{~h}$ at $37^{\circ} \mathrm{C}$. The supernatant was then removed, and $150 \mu 1$ dimethyl sulfoxide (Sigma-Aldrich) was added following $10 \mathrm{~min}$ of agitation. The optical density values were determined with an enzymelinked immunosorbent assay reader (Synergy $\mathrm{HT}^{\mathrm{TM}}$; Biotek Instruments, Inc., Winooski, VT, USA) at $490 \mathrm{~nm}$. The assays were performed in triplicate. In each group, the cells were analyzed, and the data were presented as the mean \pm standard deviation. A growth curve was generated according to the absorption values at $490 \mathrm{~nm}$ exhibited by the different groups of cells.

Soft agar colony formation assay. Plates were coated with a layer of $1 \%$ agar in $20 \%$ FBS medium. Cells were prepared in $0.66 \%$ agar in $10 \%$ FBS medium and seeded onto the above plates, which were incubated until colonies were formed. Colonies were then fixed with $4 \%$ polyoxymethylene and stained with $0.1 \%$ crystal violet, prior to be counted and photographed with a microscope (Olympus Corporation, Tokyo, Japan). Assays were conducted in triplicate, and three independent experiments were performed. 


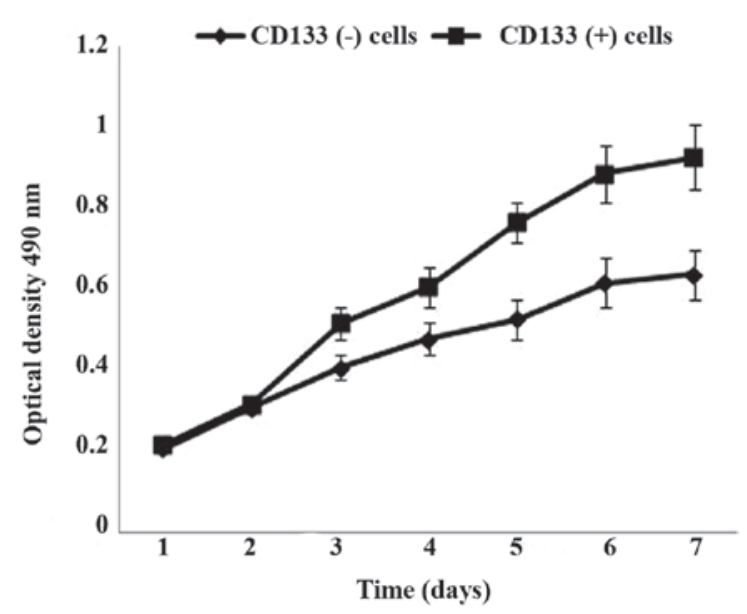

Figure 3. Cell growth in CD133 (+) and CD133 (-) cells. Measurement of proliferation rate was performed by 3-(4,5-dimethylthiazol-2-yl)-2,5diphenyltetrazolium bromide assay. CD133 (+) cells exhibited higher cell growth than CD133 (-) cells. Values are represented as the mean \pm standard deviation. $\mathrm{CD}$, cluster of differentiation.

Statistical analysis. The results are expressed as the mean \pm SEM. Statistical analysis was performed using SPSS version 13.0 software (SPSS, Inc., Chicago, IL, USA). Differences between CD133 (+) and CD133 (-) cells were compared using the two-tailed Student's t-test. $\mathrm{P}<0.05$ was considered to indicate a statistical significant difference.

\section{Results}

Gene cloning and construction of lentiviral vectors. Upon conducting PCR with the specifically designed primer pairs, PCR products containing the $\mathrm{P} 1$ promoter of the CD133, neomycin-resistance or HSV-TK genes were subjected to agarose gel electrophoresis. As shown in Fig. 1A, DNA bands of $\sim 1,800,800$ and 1,200 bp in size were observed. These DNAs were then inserted into the pMD18 vector, and the clones were identified by digestion of the vectors with different pairs of restriction enzymes and sequencing (data not shown). The results demonstrated that the P1 promoter of the CD133, neomycin-resistance and HSV-TK genes were successfully cloned in the pMD18 vector. Using gene recombination technology, the $\mathrm{P} 1$ promoter of the CD133, neomycin-resistance and HSV-TK genes were also combined with the pWPXLd vector, and the identification conducted by digestion with different pairs of restriction enzymes demonstrated that two types of vector (pWPXLd-pCD133-Neo and pWPXLd-pCD133-HSV-TK) were successfully constructed (Fig. 1B and C).

CD133 expression in CD133(+) and CD133 (-) U251 cells. U251 cells were infected with the lentiviral vector packaging particles of pWPXLd-pCD133-Neo or pWPXLd-pCD133-HSV-TK. CD133 (+) and CD133 (-) cells were obtained by adding G418 or hygromycin B for $\sim 14$ days. RT-qPCR and flow cytometry were used to detect CD133 mRNA and protein expression. The results revealed that the mRNA $(\mathrm{P}=0.029$; Fig. 2A) and protein $(\mathrm{P}<0.001$; Fig. $2 \mathrm{~B}$ and $\mathrm{C})$ expression levels of $\mathrm{CD} 133$ were significantly higher in CD133 (+) cells compared with those in CD133 (-) cells.
Cell proliferation analysis of CD133 (+) and CD133 (-) cells. To investigate the cell proliferation ability of CD133 (+) and CD133 (-) cells, an MTT assay was performed. As presented in Fig. 3, the cell proliferation ability of CD133 (+) cells was significantly higher than that of CD133 (-) cells after 3 days of culture $(\mathrm{P}=0.007)$.

Cell cycle analysis of CD133 (+) and CD133 (-) cells. The cell cycle of CD133 (+) and CD133 (-) cells was assessed by flow cytometry. As shown in Fig. 4 and Table I, the ratio of cells in the G0/G1 phases was significantly decreased in CD133 (+) cells compared with that in CD133 (-) cells $(\mathrm{P}=0.013)$. The proliferation index was remarkably higher in CD133 (+) cells $(53.823 \pm 1.105 \%)$ than in CD133 (-) cells $(22.695 \pm 1.023 \%)$ $(\mathrm{P}<0.001)$.

Soft agar colony formation. The in vitro invasive ability of CD133 (+) and CD133 (-) cells was estimated by soft agar colony formation assay. Compared with CD133 (-) cells, the colony number of CD133 (+) cells was significantly increased $(\mathrm{P}<0.001)$ (Fig. 5).

\section{Discussion}

The CD133 antigen is a five-transmembrane domain glycoprotein, which has been used to identify and isolate CSCs in various tumors, including colon cancer, prostate cancer and hepatocellular carcinoma (18). In gliomas, the role of CD133 as a marker of stem-like glioma cells has been widely investigated, since it identifies cells that are able to initiate neurosphere growth and form heterogeneous tumors when transplanted in immunocompromised mice (19). FACS and MACS are the most common methods for isolating CSCs, but these approaches require costly antibodies and dedicated equipment, and isolate only low numbers of viable cells (12). The present study established a novel method for obtaining CD133 (+) and CD133 (-) U251 cells.

In the current study, gene recombination technology was successfully used to construct two types of gene expression vectors, which were stably transfected in the U251 cell line. CD133 (+) and CD133 (-) U251 cells were obtained by adding G418 or hygromycin B to the culture medium for 14 days. The results indicated that the protein expression level of CD133 in U251 cells was $\sim 5 \%$, which demonstrated that there were few GSCs in the U251 glioma cells. Specifically, the present data demonstrated that CD133 protein expression was significantly higher in CD133 (+) cells compared with that in CD133 (-) cells.

The biological identification of CD133 (+) and CD133 (-) cells is mainly based on the properties of CSCs, since these cells i) exhibit tumorigenic potential in vivo and in vitro; ii) possess the properties of self-renewal and differentiation; iii) express various typical CSCs markers; iv) generate clonally derived cells that form neurospheres; and v) possess high proliferation potential and multidrug resistance $(20,21)$. The study of CSCs is of importance and value for controlling and preventing tumor growth, recurrence and prognosis. Increased knowledge regarding CSCs may aid to better treat and prevent tumors. The present study observed that CD133 (+) cells highly expressed the CD133 surface marker, whereas there was very limited expression of CD133 in CD133 (-) cells. 
Table I. Cell cycle distribution of CD133 (+) and CD133 (-) cells (n=3).

\begin{tabular}{llcc}
\hline & \multicolumn{3}{c}{ Cell cycle distribution (\%) } \\
\cline { 2 - 4 } Group & G0/G1 & $\mathrm{S}$ & $\mathrm{G} 2 / \mathrm{M}$ \\
\hline CD133 (+) cells & $47.175 \pm 1.312^{\mathrm{a}}$ & $36.375 \pm 1.541^{\mathrm{a}}$ & $16.517 \pm 1.101^{\mathrm{a}}$ \\
CD133 (-) cells & $78.312 \pm 1.878$ & $17.754 \pm 1.621$ & $3.732 \pm 0.531$ \\
\hline
\end{tabular}

${ }^{\mathrm{a}} \mathrm{P}<0.05$. $\mathrm{CD}$, cluster of differentiation.

A

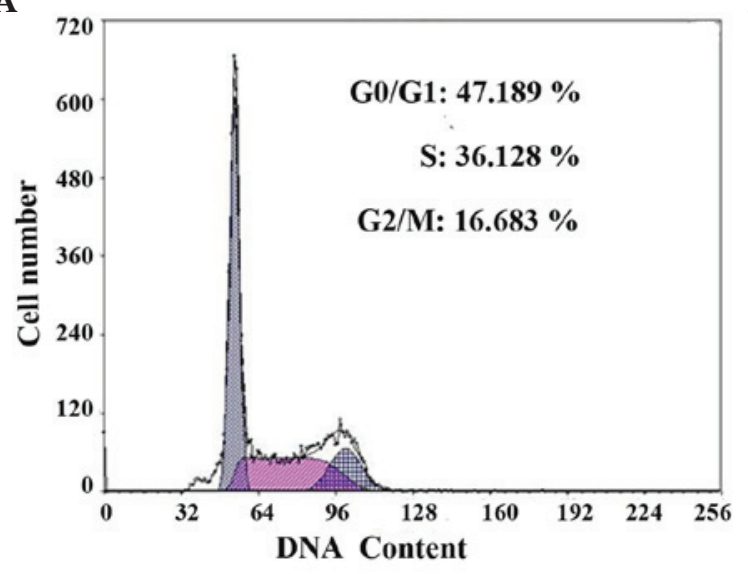

B

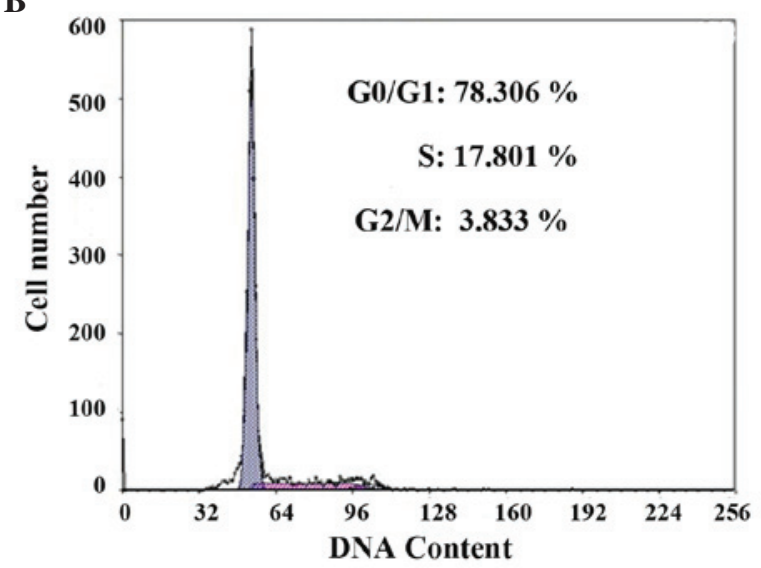

Figure 4. Cell cycle distribution analysis of (A) CD133 (+) and (B) CD133 (-) cells. Histograms were representative of three independent experiments. CD, cluster of differentiation.

A

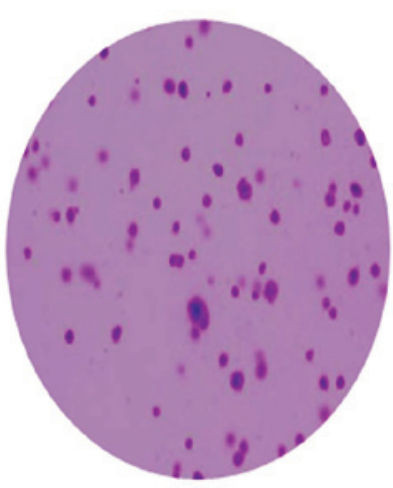

B

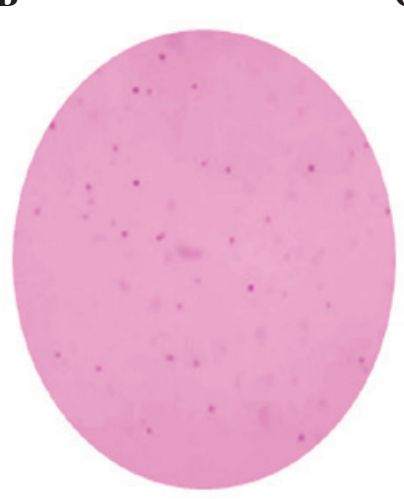

C

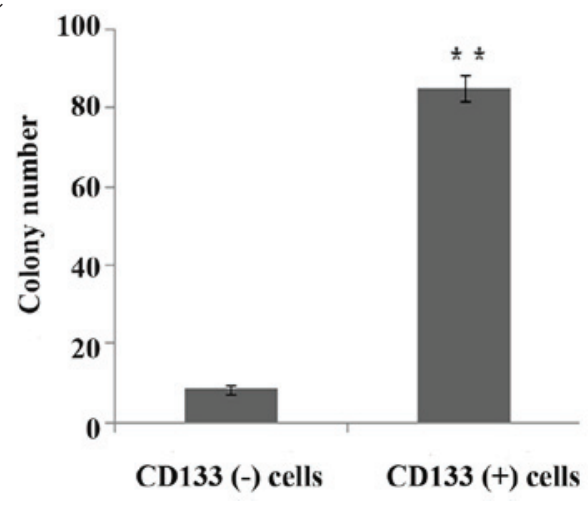

Figure 5. The invasive ability of (A) CD133 (+) and (B) CD133 (-) cells was evaluated by soft agar formation assay. Images are representative of three independent experiments. (C) The results were quantified based on the findings from three experiments, and were represented as the mean \pm standard deviation. ${ }^{* *} \mathrm{P}<0.05$ vs. control. $\mathrm{CD}$, cluster of differentiation.

Importantly, the current results demonstrated that CD133 (+) cells have higher cell proliferation ability, proliferation index and invasive ability than CD133 (-) cells, which suggested that CD133 (+) cells exhibit certain biological characteristics and functions of CSCs.

However, there are a number of limitations that affect the present study. First, although CD133 is the most common marker used for CSC sorting in gliomas, various studies have questioned the utility of CD133 in the isolation of GSCs $(19,22)$. Second, not only CD133 (+) cells but also CD133 (-) cells are able to self-renew, regenerate tumors in vivo and in vitro, and possess stem cell characteristics and tumorigenic potential (23). In addition, certain studies have proposed that there is not a hierarchical association between CD133 (+) and CD133 (-) cells forming neurospheres (24). Third, CD133, as a marker of GSCs, is not widely accepted by a number of studies, and has not been detected in several fresh glioma specimens or established glioma cell lines $(22,25,26)$.

In conclusion, the present study successfully established a novel approach to obtain GSCs from U251 glioma cells based on the P1 promoter of CD133, which may be useful for future studies on CSCs. 


\section{Acknowledgements}

The present study was supported by the Department of Public Health of Jilin Province (Changchun, China; grant no.2014Q025), the Supporting Program of Bethune Medical Research of Jilin University (Changchun, China; grant no. 2013207058) and the Jilin Science and Technology Development Plan of China (Changchun, China; grant nos. 201201060 and 201215078).

\section{References}

1. Wen PY and Reardon DA: Neuro-oncology in 2015: Progress in glioma diagnosis, classification and treatment. Nat Rev Neurol 12: 69-70, 2016.

2. Wei X, Wang J, He J, Ma B and Chen J: Biological characteristics of CD133(+) cancer stem cells derived from human laryngeal carcinoma cell line. Int J Clin Exp Med 7: 2453-2462, 2014.

3. Parajuli P, Anand R, Mandalaparty C, Suryadevara R, Sriranga PU, Michelhaugh SK, Cazacu S, Finniss S, Thakur A, Lum LG, et al: Preferential expression of functional IL-17R in glioma stem cells: Potential role in self-renewal. Oncotarget 7: 6121-6135, 2016.

4. Najbauer J, Kraljik N and Németh P: Glioma stem cells: Markers, hallmarks and therapeutic targeting by metformin. Pathol Oncol Res 20: 789-797, 2014

5. Yasumoto Y, Miyazaki H, Vaidyan LK, Kagawa Y, Ebrahimi M, Yamamoto Y, Ogata M, Katsuyama Y, Sadahiro H, Suzuki M and Owada Y: Inhibition of fatty acid synthase decreases expression of stemness markers in glioma stem cells. PLoS One 11: e0147717, 2016.

6. Singh SK, Hawkins C, Clarke ID, Squire JA, Bayani J, Hide T, Henkelman RM, Cusimano MD and Dirks PB: Identification of human brain tumour initiating cells. Nature 432: 396-401, 2004.

7. Nie S, Gurrea M,Zhu J, Thakolwiboon S, Heth JA, Muraszko KM, Fan X and Lubman DM: Tenascin-C: A novel candidate marker for cancer stem cells in glioblastoma identified by tissue microarrays. J Proteome Res 14: 814-822, 2015.

8. Park EK, Lee JC, Park JW, Bang SY, Yi SA, Kim BK, Park JH, Kwon SH, You JS, Nam SW, et al: Transcriptional repression of cancer stem cell marker CD133 by tumor suppressor p53. Cell Death Dis 6: e1964, 2015.

9. Tabu K, Sasai K, Kimura T, Wang L, Aoyanagi E, Kohsaka S, Tanino M, Nishihara $\mathrm{H}$ and Tanaka S: Promoter hypomethylation regulates CD133 expression in human gliomas. Cell Res 18 1037-1046, 2008.

10. Ren F, Sheng WQ and Du X: CD133: A cancer stem cells marker, is used in colorectal cancers. World J Gastroenterol 19: 26032611, 2013.

11. Joo KM and Nam DH: Prospective identification of cancer stem cells with the surface antigen CD133. Methods Mol Biol 568: 57-71, 2009.

12. Kievit FM, Florczyk SJ, Leung MC, Wang K, Wu JD, Silber JR, Ellenbogen RG, Lee JS and Zhang M: Proliferation and enrichment of CD133(+) glioblastoma cancer stem cells on 3D chitosan-alginate scaffolds. Biomaterials 35: 9137-9143, 2014.

13. Livak KJ and Schmittgen TD: Analysis of relative gene expression data using real-time quantitative PCR and the 2(-Delta Delta C(T)) Method. Methods 25: 402-408, 2001.
14. Cutler MJ, Lowthers EL, Richard CL, Hajducek DM, Spagnuolo PA and Blay J: Chemotherapeutic agents attenuate CXCL12-mediated migration of colon cancer cells by selecting for CXCR4-negative cells and increasing peptidase CD26. BMC Cancer 15: 882, 2015.

15. Zhang Y, Wang Y, Du Z, Wang Q, Wu M, Wang X, Wang L, Cao L, Hamid AS and Zhang G: Recombinant human decorin suppresses liver HepG2 carcinoma cells by p21 upregulation. Onco Targets Ther 5: 143-152, 2012.

16. Guthrie HD, Welch GR, Cooper BS, Zakaria AD and Johnson LA: Flow cytometric determination of degraded deoxyribonucleic acid in granulosa cells to identify atretic follicles during preovulatory maturation in the pig. Biol Reprod 50: 1303-1311, 1994.

17. Hamid AS, Li J, Wang Y, Wu X, Ali HA, Du Z, Bo L, Zhang Y and Zhang G: Recombinant human decorin upregulates p57KIP ${ }^{2}$ expression in HepG2 hepatoma cell lines. Mol Med Rep 8: 511-516, 2013.

18. Ffrench B, Gasch C, O'Leary JJ and Gallagher MF: Developing ovarian cancer stem cell models: Laying the pipeline from discovery to clinical intervention. Mol Cancer 13: 262, 2014.

19. Brescia P, Ortensi B, Fornasari L, Levi D, Broggi G and Pelicci G: CD133 is essential for glioblastoma stem cell maintenance. Stem Cells 31: 857-869, 2013

20. Vescovi AL, Galli R and Reynolds BA: Brain tumour stem cells. Nat Rev Cancer 6: 425-436, 2006.

21. Cho DY, Lin SZ, Yang WK, Hsu DM, Lin HL, Lee HC, Lee WY and Chiu SC: The role of cancer stem cells (CD133(+)) in malignant gliomas. Cell Transplant 20: 121-125, 2011.

22. Wang J, Sakariassen PØ, Tsinkalovsky O, Immervoll H, Bøe SO, Svendsen A, Prestegarden L, Røsland G, Thorsen F, Stuhr L, et al: CD133 negative glioma cells form tumors in nude rats and give rise to CD133 positive cells. Int J Cancer 122: 761-768, 2008.

23. Brescia P, Richichi C and Pelicci G: Current strategies for identification of glioma stem cells: Adequate or unsatisfactory? J Oncol 2012: 376894, 2012.

24. Sun T, Chen G, Li Y, Xie X, Zhou Y and Du Z: Aggressive invasion is observed in CD133/A2B5+ glioma-initiating cells. Oncol Lett 10: 3399-3406, 2015.

25. Joo KM, Kim SY, Jin X, Song SY, Kong DS, Lee JI, Jeon JW, Kim MH, Kang BG, Jung Y, et al: Clinical and biological implications of CD133-positive and CD133-negative cells in glioblastomas. Lab Invest 88: 808-815, 2008.

26. Son MJ, Woolard K, Nam DH, Lee J and Fine HA: SSEA-1 is an enrichment marker for tumor-initiating cells in human glioblastoma. Cell Stem Cell 4: 440-452, 2009. 